Dhaka Univ. J. Biol. Sci. 24(2): 147-152, 2015 (July)

\title{
CHEMICAL AND BIOLOGICAL POTENTIALITIES OF THE ETHYL ACETATE EXTRACTS OF DRYNARIA QUERCIFOLIA TUBER AND LEAF
}

\author{
Wardatul Jannat Anamika, Miraj Kobad Chowdhury, Md. Ausrafuggaman \\ Nahid, Abu Shara Shamsur Rouf ${ }^{1}$ and M. Aftab Uddin* \\ Department of Genetic Engineering and Biotechnology, University of Dhaka, \\ Dhaka-1000, Bangladesh
}

Key words: Chemical and biological potentialities, Ethyl acetate extracts, Drynaria quercifolia

\begin{abstract}
The ethyl acetate extracts of Drynaria quercifolia tubers and leaves were studied for their chemical and biological potentialities. The tuber extract was enriched with more reducing power compared to the leaf extract. But, the phenolic content was higher in the leaf extract compared to the tuber extracts. However, both the extracts were comparably cytotoxic and showed broadspectrum antimicrobial activity. The antimicrobial compound in the tuber extract was nonpolar. The findings suggested that the ethyl acetate extracts of $D$. quercifolia may have active principles for the development of promising phytotherapeutics.
\end{abstract}

\section{Introduction}

Herbal medicines have been used to treat different diseases since ancient times ${ }^{(1)}$. Medicinal plants are a subject of research interest due to long folkloric use with minimum or no side-effects( ${ }^{(2)}$. A large number of different medicinal herbs and plants have been investigated for their antioxidant and antibacterial activities ${ }^{(3)}$. Plants have been in focus of most researches because a number of biologically and medicinally important compounds had been isolated from different plants. With the increase in frequency of life threatening infections, researchers are exploring different plant extracts for the treatment of many diseases ${ }^{(4)}$. Although a number of flowering plants have been investigated for their biological activities and chemical constituents, other medicinal plants remained almost unnoticed.

Drynaria quercifolia, commonly known as the oak-leaf fern, is an epiphyte with rhizome and deeply pinnatifid foliage fronds. This plant is native to Asian continent and grows widely in Bangladesh(5). This plant had been used ethnomedicinally to get relief from the symptoms of different diseases, and a few studies showed the antibacterial, antipyretic, anti-helminthic activities, thrombolytic potentials of the crude tuber extracts. Some compounds like naringin, epifriedelinol and friedelin have been isolated from this plant ${ }^{(6)}$.

*Author for correspondence: <draftabu@gmail.com>. ${ }^{1}$ Department of Pharmaceutical Technology, University of Dhaka, Dhaka-1000, Bangladesh. 
In the present investigation, the chemical and biological activities of ethyl acetate extracts of $D$. quercifolia tuber and leaf were studied with the intention of isolating active principles.

\section{Materials and Methods}

Drynaria quercifolia plants were collected from the University of Dhaka campus between May and June, 2012 and was identified by Bangladesh National Herbarium (accession number 37592). Tuber and leaf samples were separated from the plant and were dried under shadow for 10 days. Then the samples were crushed into powder using mechanical grinder. One hundred and fifty $\mathrm{g}$ of dried leaf powder and $700 \mathrm{~g}$ of dried tuber powder was soaked in $600 \mathrm{ml}$ or $2,800 \mathrm{ml}$ of ethyl acetate (ACS grade, BDH, USA), respectively, for 5 days with gentle shaking. The extracts were collected as filtrate through Whatman filter paper (Grade 4) and evaporated at low temperature $\left(45^{\circ} \mathrm{C}\right)$ through rotary evaporator under reduced pressure ${ }^{(7)}$. Each extract was examined physically and the weight was measured. On an average, $1.8 \mathrm{~g}(0.26 \% \mathrm{w} / \mathrm{w})$ of tuber extract and $4.2 \mathrm{~g}(2.8 \% \mathrm{w} / \mathrm{w})$ leaf extract was obtained. Total reducing power of the extracts was determined as ascorbic acid equivalence (AAE) ${ }^{(8)}$. One hundred $\mu \mathrm{g}$ extract was dissolved in dimethyl sufoxide (DMSO) and mixed up to $2 \mathrm{ml}$ with $0.2 \mathrm{M}$ phosphate buffer ( $\mathrm{pH}$ 6.6). Two $\mathrm{ml}$ of $1 \%(\mathrm{w} / \mathrm{v}) \mathrm{K}_{3} \mathrm{Fe}(\mathrm{CN})_{6}$ (Sigma, USA) was added and incubated at $50^{\circ} \mathrm{C}$ for 40 minutes. The reaction was stopped by adding $2 \mathrm{ml}$ of $10 \%(\mathrm{w} / \mathrm{v})$ tricholoroacetic acid (Sigma, USA), mixed well and centrifuged at $3000 \mathrm{rpm}$ for 10 minutes. Then, $2.5 \mathrm{ml}$ deionized distilled water was mixed with $2 \mathrm{ml}$ of the supernatant and $0.4 \mathrm{ml}$ of $0.1 \%(\mathrm{w} / \mathrm{v})$ aqueous solution of iron(III) chloride. After mixing well, absorbance was measured at $700 \mathrm{~nm}$ using spectrophotometer. Ascorbic acid of $0-100$ $\mu \mathrm{g}$ used as standard positive control and a blank DMSO was used as negative control.

Total phenolic content of the extracts were measured as gallic acid equivalence (GAE) by Folin-Ciocalteu method with appropriate control(8). One hundred $\mu \mathrm{g}$ extract was dissolved in DMSO and mixed with deionized distilled water up to $2 \mathrm{ml}$. The solution was treated with $200 \mu$ Folin-Ciocalteu reagent (Sigma, USA) and was incubated for 5 minutes at room temperature. Then, $2 \mathrm{ml}$ of $7 \%(\mathrm{w} / \mathrm{v})$ sodium carbonate was added and mixed well. Finally $800 \mu \mathrm{l}$ of deionized distilled water was added, incubated for 90 minutes at room temperature and then absorbance was measured at $750 \mathrm{~nm}$ using spectrophotometer. Each experiment was performed in triplicate.

Cytotoxic property of the extracts was evaluated on brine shrimp (Artemia salina) nauplii according to the Meyer protocol with some modification(7). Simply, shrimp eggs were collected from the local market and were hatched in simulated sea water. The extract sample was dissolved in DMSO and diluted in saline to obtain final concentration ranging from $0-100 \mu \mathrm{g} / \mathrm{ml}$ during the experiment. Vincristine sulphate was used as a positive control. For each sample, minimum 10 living nauplii were taken in triplicate. 
Then the nauplii were kept in dark at room temperature for 24 hours and numbers of dead and living nauplii were counted. Then the per cent mortality and correlation between concentration and mortality was analyzed to calculate the $\mathrm{LC}_{50}$ values. Antimicrobial activity was performed by agar-well diffusion method(7). Candida albicans and five multi-drug resistant bacterial strains were used. The bacterial strains were Staphylococcus saprophyticus and S. aureus, E. coli DH-5a, E. coli pUC19, and E. coli pGLO. The zone of inhibition was measured in $\mathrm{mm}$.

Thin-layer chromatography (TLC) was used to separate the active compound responsible for the antimicrobial activity of tuber extract ${ }^{(9)}$. Tuber extract was dissolved in $50 \mathrm{ml}$ deionized distilled water. Fifty $\mathrm{ml}$ ethyl acetate was added to the solution and mixed well to obtain an aqueous fraction and an ethyl acetate soluble fraction and the fractions were separated using a separating funnel. The ethyl acetate soluble fraction was spotted on analytical TLC plate and compounds were separated with ethyl acetate: petroleum ether (1:9) solvent system. Then the plate was observed under UV light (254 $\mathrm{nm}$ ). A single band collected from the plate was diffused overnight at $4^{\circ} \mathrm{C}$ on a MullerHinton agar plate inoculated with bacteria. Then the agar plate was incubated at $37^{\circ} \mathrm{C}$ to evaluate the antimicrobial activity of the compound found on the TLC plate. All the experiments were performed in triplicate and the data were analyzed using Microsoft Excel at $95 \%$ confidence interval.

\section{Results and Discussion}

Plant extracts and compounds obtained by direct extraction from a native producer or by semi-synthesis are now considered as biotechnology medicine ${ }^{(10)}$. Medicinal application of Drynaria quercifolia has been described in ethnomedicine ${ }^{(11)}$. Thereby, activities of the ethyl acetate extracts of this plant were evaluated in this study. The colour of leaf extract was dark green and the nature was light sticky or oily. On the other hand, the tuber extract was dark brown in colour and sticky in nature. Both the extracts had pungent odour and were bitter in taste.

Using ascorbic acid standard, total reducing power of each extracts were evaluated as ascorbic acid extract (AAE). AAE for tuber extract and leaf extract was $7.08 \pm 0.75$ and $4.84 \pm 0.48 \mathrm{mg}$ ascorbic acid per gram of each extracts, respectively indicating that the tuber extract had significantly more total reducing power $(p$ value $=0.012)$ than that of the leaf extract. The estimated total phenolic content of the tuber extract and the leaf extract was $1.98 \pm 0.62$ and $10.35 \pm 1.53 \mathrm{mg}$ gallic acid equivalent (GAE) per gram of extract, respectively (Table 1). These results suggested that leaf extract had significantly higher phenolics $(p=0.001)$ compared to the tuber extract.

Brine shrimp lethality bioassay was performed to determine the $\mathrm{LC}_{50}$ value of individual extract(12). The $\mathrm{LC}_{50}$ value of tuber extract was $53.33 \pm 1.57 \mu \mathrm{g} / \mathrm{ml}$, whereas the same value for leaf extract was $44.68 \pm 1.47 \mu \mathrm{g} / \mathrm{ml}$. The difference in cytotoxicity between 
these extracts was not significant enough $(p=0.12)$. For both the extracts, there was a strong linear correlation between the concentration and the percentage of mortality $\left(R^{2}\right.$ for the tuber extract $=0.996$ and for the leaf extract $=0.979$ ) at $95 \%$ confidence interval. The $\mathrm{LC}_{50}$ value of the positive control was similar as published before ${ }^{(7)}$. These data suggested that both extracts were enriched with bioactive compounds.

Table 1. Reducing power and phenolic content of the extracts of Drynaria quercifolia.

\begin{tabular}{lcc}
\hline Type of extract & Total reducing power ${ }^{\mathrm{a}}$ & Phenolic content $^{\mathrm{b}}$ \\
\hline Ethyl acetate tuber extract & $7.08 \pm 0.75$ & $1.98 \pm 0.62$ \\
Ethyl acetate leaf extract & $4.84 \pm 0.48$ & $10.35 \pm 1.53$ \\
p-value & 0.012 & 0.001 \\
\hline
\end{tabular}

${ }^{a} \mathrm{mg}$ ascorbic acid equivalence per $\mathrm{g}$ of extract $\pm \mathrm{Sd}$, and ${ }^{\mathrm{b}}$ gallic acid equivalence per $\mathrm{g} \pm \mathrm{Sd}$.

When $100 \mu \mathrm{g} / \mu \mathrm{l}$ extract was applied, both the extracts showed significant

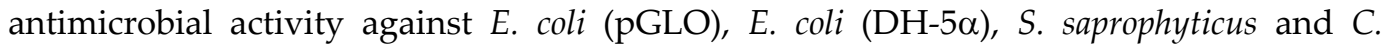
albicans (Table 2). However, the tuber extract was also active against E. coli (pUC19) but the leaf extract did not possess activity against this strain. Both the extracts did not show any activity against $S$. aureus (Table 2).

Table 2. Antimicrobial activities of the extracts of Drynaria quercifolia.

\begin{tabular}{|c|c|c|c|}
\hline \multirow{3}{*}{ Name of bacteria } & \multicolumn{3}{|c|}{ Inhibition zone $(\mathrm{mm} \pm \mathrm{Sd})$} \\
\hline & \multirow{2}{*}{$\begin{array}{c}\text { Tuber extract }(\mu \mathrm{g} / \mu \mathrm{l}) \\
100\end{array}$} & \multicolumn{2}{|c|}{ Leaf extract $(\mu \mathrm{g} / \mu \mathrm{l})$} \\
\hline & & 10 & 100 \\
\hline Candia albicans & $23 \pm 1$ & $10 \pm 1$ & $35 \pm 1$ \\
\hline Escherichia coli $(\mathrm{DH}-5 \mu)$ & $23 \pm 1$ & $15 \pm 1$ & $45 \pm 1$ \\
\hline Escherichia coli (pGLO) & $15 \pm 1$ & - & $20 \pm 1$ \\
\hline Escherichia coli (pUC19) & $26 \pm 1$ & - & - \\
\hline Staphylococcus saprophyticus & $25 \pm 1$ & $14 \pm 1$ & $45 \pm 1$ \\
\hline Staphylococcus aureus & - & - & - \\
\hline
\end{tabular}

Furthermore, at $10 \mu \mathrm{g} / \mu \mathrm{l}$ concentration, tuber extract completely failed to show any antimicrobial activity but not the leaf extract. The leaf extract showed antimicrobial

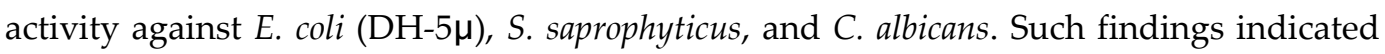
that the minimum inhibitory concentrations (MIC) of the leaf extract for these microorganisms were $10 \mu \mathrm{g} / \mu \mathrm{l}$, otherwise the MIC values were $100 \mu \mathrm{g} / \mu \mathrm{l}$ for all the sensitive microorganisms. The highest diameter of zone of inhibition was observed for

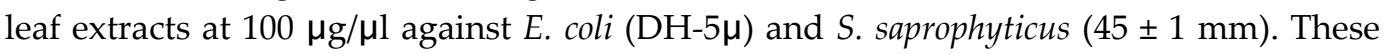
results indicated that the leaf extract was more active against tested pathogenic microorganisms. However, the spectrum of the antimicrobial activity of the tuber extract 
at $100 \mu \mathrm{g} / \mu \mathrm{l}$ concentration was broader compared to the leaf extract at the same concentration. Thereby, it was hypothesized that the tuber extract may contain a very low concentration of highly potent antimicrobial compound(s). Hence, the tuber extract was further fractionated and was run on a TLC plate. A single band was observed when the compounds in this fraction were separated with ethyl acetate: petroleum ether $(1: 9)$ solvent system (Fig. 1a)

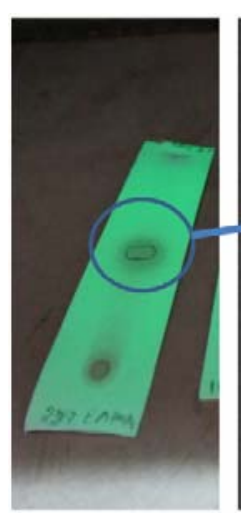

(1a)

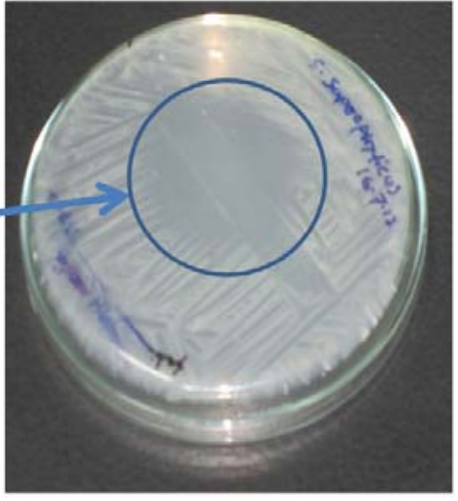

(1b)

Fig. 1a. TLC separation pattern of tuber extract. 1b. Bioautography of ethyl acetate extract of Drynaria quercifolia tubers on Staphylococcus saprophyticus after thin-layer chromatography (TLC).

When this band was diffused and tested for antimicrobial activity, a distinct clear zone was observed in accordance with the position of the band. Also, no clear zone was observed for rest of the TLC strips (Fig. 1b). Such finding indicated that the compound observed as a band was nonpolar and also possessed antimicrobial activity. This compound will be isolated, purified and identified using ${ }^{1} \mathrm{HNMR}$ spectroscopy later. From the above studies, it can be suggested that D. quercifolia may be a good source of folk medicine.

\section{Acknowledgement}

The authors thankfully acknowledge the authority of the University Grants Commission and Centre for Advanced Studies and Research in Biological Sciences, University of Dhaka for financial assistance. The authors are grateful to the Higher Education Quality Enhancement Project (HEQEP) authority for providing modern research facilities at the Department of Genetic Engineering and Biotechnology, University of Dhaka.

\section{References}

1. Bayan L, PH Koulivand and A Gorji 2014. Garlic: A review of potential therapeutic effects. Avicenna J. Phytomed. 4: 1-14. 
2. Deng X, M Jiang, X Zhao and J Liang 2014. Efficacy and safety of traditional Chinese medicine for the treatment of acquired immunodeficiency syndrome: a systematic review. J. Trad. Chin. Med. 34: 1-9.

3. Muluye RA, Y Bian and PN Alemu 2014. Anti-inflammatory and antimicrobial effects of heatclearing chinese herbs: A current review. J. Tradit. Complement. Med. 4: 93-98.

4. Hamidpour M, R Hamidpour, S Hamidpour and M Shahlari 2014. Chemistry, pharmacology, and medicinal property of sage (Salvia) to prevent and cure illnesses such as obesity, diabetes, depression, dementia, lupus, autism, heart disease, and cancer. J. Tradit. Complement. Med. 4: 82-88.

5. Wangensteen H, L Klarpas, M Alamgir, AB Samuelsen and KE Malterud 2013. Can scientific evidence support using Bangladeshi traditional medicinal plants in the treatment of diarrhoea? A review on seven plants. Nutrients 5: 1757-1800.

6. Khan A, E Haque, M Mukhlesur Rahman, A Mosaddik, M Rahman and N Sultana 2007. Isolation of antibacterial constituent from rhizome of Drynaria quercifolia and its sub-acute toxicological studies. DARU J. Pharm. Sci. 15: 205-211.

7. Chowdhury MK, N Ahsan and AA Akhand 2009. Comparative antibacterial effects of leaf extracts of Azadirachta indica and Terminalia arjuna and aggregation of bacterial proteins. J. Trop. Mdsed. Plants 10: 31-38.

8. Olugbami JO, MA Gbadegesin and OA Odunola 2015. In vitro free radical scavenging and antioxidant properties of ethanol extract of Terminalia glaucescens. Pharmacognosy Res. 7: 49-56.

9. Penesyan A, J Tebben, M Lee, T Thomas, S Kjelleberg, T Harder and S Egan 2011. Identification of the antibacterial compound produced by the marine epiphytic bacterium Pseudovibrio sp. D323 and related sponge-associated bacteria. Marine Drugs 9: 1391-1402.

10. Schmidt B, DM Ribnicky, A Poulev, S Logendra, WT Cefalu and I Raskin 2008. A natural history of botanical therapeutics. Metabolism 57: 3-9.

11. Khan A, MH Islam, ME Islam, MAA Al-Bari, MS Parvin, MA Sayeed and ME Haque 2014. Pesticidal and pest repellency activities of rhizomes of Drynaria quercifolia (J. Smith) against Tribolium castaneum. Biol. Res. 47: 51.

12. Meyer BN, NR Ferrigni, JE Putnam, LB Jacobsen, DE Nichols and JL McLaughlin 1982. Brine shrimp: a convenient general bioassay for active plant constituents. Planta Med. 45: 31-34. 